SYSTEMATIC REVIEW

\title{
Community based programs to prevent poisoning in children 0-15 years
}

\author{
J Nixon, A Spinks, C Turner, R McClure
}

Injury Prevention 2004;10:43-46. doi: 10.1136/ip.2003.003822

See end of article for authors' affiliations

.....................

Correspondence to: Cathy Turner, Injury Research Unit, School of Population Health, Mayne Medical School, University of Queensland, Herston Rd, Herston, QLD, Australia 4006;

C.Turner@sph.uq.edu.au
Objective: Community based models for injury prevention have become an accepted part of the overall injury control strategy. This systematic review of the scientific literature examines the evidence for their effectiveness in preventing poisoning in children 0-15 years of age.

Methods: A comprehensive search of the literature was performed using the following study selection criteria: community based intervention study; target population was children under 15 years; outcome measure was poisoning rates; and either a community control or an historical control was used in the study design. Quality assessment and data abstraction were guided by a standardized procedure and performed independently by two authors. Data synthesis was in tabular and text form with meta-analysis not being possible due to the discrepancy in methods and measures between the studies.

Results: The review found only four studies, which met all the inclusion criteria. Only two studies used a trial design with a contemporary control and only one study provided convincing evidence of an effective community program for reducing poisoning in children.

Conclusion: There is a paucity of research studies in the literature from which evidence regarding the effectiveness of community based childhood poisoning prevention programs can be obtained and hence a clear need to increase the effort on developing this evidence base.
$\mathrm{T}$ he dramatic reduction, over the last 30 years, in fatal poisoning in young children is frequently cited as a signature example of the success of injury prevention and control. ${ }^{1-3}$ Poisoning is generally defined by injury prevention practitioners as an inclusive category within the overall term "injury" and with respect to this age group it usually involves unintentional ingestion of medicines and common household products. While the incidence of fatal poisonings has reduced, there remains a substantial number of hospital admissions and emergency department attendances, in Australia, for treatment of childhood ingestion and the use of poisons centres for telephone advice to parents after ingestions of poisons by children, remains high. ${ }^{4}$ Poisoning remains second (after falls) on the list of external causes for admission to hospital in the 0-4 age group. ${ }^{5}$ Furthermore, studies from Australia and New Zealand show that the frequency of hospital admissions and emergency department presentations for poisoning have either not decreased in recent years ${ }^{467}$ or have actually increased..$^{5}$ There remains some debate as to whether these numbers indicate level of parental and medical staff concern rather than substantive cases of poisoning, ${ }^{9}$ and it is suggested that to some extent further reductions in hospital cases could be achieved at no increased risk to children by changing the management of suspected ingestion. However, while fatal poisonings are now rare, ${ }^{13}$ the persistently high incidence of childhood poisonings necessitates a renewed search for effective strategies to reduce the burden of ingestion related harm in young children. Community based, multistrategy approaches to the problem of childhood injury is currently advocated. ${ }^{10}$

Community based models are characterized as having a shared ownership of the injury problem and its solution, by experts and community members, and joint responsibility for determining appropriate interventions. ${ }^{10}$ Studies of how children access poisons ${ }^{5}$ suggest that the most vulnerable time is when the poisons are in use and that safe packaging alone cannot compensate for unsafe storage or use, ${ }^{11}$ and thus improved safety of home storage of medications ${ }^{7}$ and improved home dispensing practice is required. ${ }^{5}$ Changes to the fixed environment need to be supported by appropriate implementation measures such as regulation and education for industry and the community, with clear labelling (and clear administration instructions) on the package, ${ }^{5}$ parental education and improved supervision, ${ }^{5}$ ongoing paediatric counselling, and increased accessibility and affordability. ${ }^{12}$ Community based programs need to be targeted to specific age groups and specific substances, and the range of products for which child resistant closures (CRCs) is legislated needs to be increased along with efforts to improve the efficacy of the CRCs (including dose related packaging) themselves. ${ }^{5}$ It is clearly recognised by all authors that successful implementation of a poisoning prevention program in communities depends upon embedding the countermeasures, such as CRCs, in the contextual practices of social structures and that a multistrategy program for preventing childhood poisoning is essential. Effective injury prevention is more than the identification of countermeasures, which are efficacious under research conditions. It depends upon making these measures work at the community level in the form of effective programs which reduce community level indicators of injury outcome. ${ }^{12}$

The aim of this paper is to summarise the scientific literature relating to high quality evidence of the effectiveness of community based interventions to reduce poisoning mortality and morbidity in children $0-15$ years of age.

\section{METHODS}

A search for published studies was conducted using WebSPIRS as a search tool for Medline (1966-2003), CINAHL (1982-2003), and PsycINFO (1872-2003) databases. The following search strategy was used:

(child* OR adolescent OR pediatric OR paediatric) AND (strateg* OR intervention* OR program* OR prevent*) AND (poison* OR ingest*) AND (communit* OR population*).

The initial deliberately broad search strategies yielded over 21000 studies based on child poisoning related search terms 
and over 130000 studies based on intervention search terms. When these terms were combined the number of studies reduced to around 4000. After limiting the search to interventions conducted with a community or population setting the search yielded 923 abstracts from Medline, 380 abstracts from CINAHL, and 23 abstracts from PsycINFO. These abstracts were screened by the second author based on the study selection criteria, which led to the retrieval of full texts for 17 studies.

An examination of the references for each of these articles warranted obtaining the abstracts for additional studies, however closer examination of these abstracts did not identify any further studies for possible inclusion. A separate hand search of the journal Injury Prevention (1995-2003) was performed; however, no further articles were identified.

Ten of the 17 studies retrieved were discarded as they either lacked an evaluation component or did not meet the definition for a community based intervention. ${ }^{10}$ The third and fourth authors independently examined the final seven articles according to the following study selection criteriathat is, that the study:

- Be a community based intervention.

- Have a target population of children under 15 years.

- Include poisoning rates as the outcome measure.

- Include either a community control or historical control in the study design.

Four studies met all the inclusion criteria for this review and were subject to a further data extraction process conducted independently by the third and fourth authors with the second author acting to reconcile differences. This process was guided by a standardized abstraction procedure developed to improve the evaluation of the quality of studies selected in a review. ${ }^{13}$ The form constructed for the purpose of this review is available at the following website: http:// www.ipca.com.au. Each study was independently assessed for the quality of the execution of the study by the third and fourth authors. The results of the data abstraction process are outlined in table 1 .

\section{RESULTS}

This review found only four studies, which met all the inclusion criteria. Two studies were designed with a community control for comparison with the intervention community. ${ }^{14}{ }^{15}$ A further two studies were designed using the intervention community as an historical control in a before-after design. ${ }^{16}{ }^{17}$ Meta-analysis was not possible due to the diversity of the interventions and the outcome measures reported in each of the studies reviewed. Three studies were not selected for this review as no evaluation of poisoning outcomes were included. ${ }^{18-20}$

\section{Studies evaluating a community based intervention using a control community design}

A community based injury prevention program designed to reduce poisoning rates in $0-5$ year olds was implemented as one of five projects initiated in a Statewide Childhood Injury Prevention Program. ${ }^{14}$ The intervention was implemented by nine cities in Massachusetts with the baseline and postprogram poisoning rates of these communities compared to those obtained from five control communities. The poison prevention intervention involved community wide promotion of the Massachusetts Poison Control System's telephone information service and public education about poison prevention. Injury counseling was provided for parents of young children by pediatricians using the developmentally based Framingham safety surveys. Household hazard identification and control was undertaken through systematic home safety inspections by specially trained local board of health staff. While the control communities were originally matched demographically based on census data, their demographic distribution changed about the time of the study to include higher proportions of poorer Hispanic households. Results were stratified and analyzed according to three levels of median family income and no association was found between the intervention and a reduction in poisoning rates after the campaign. A telephone survey was conducted to assess the program from which it was estimated that pediatrician counseling was provided for only $21 \%$ of the target households, home hazard inspection was performed on only $5 \%$ and poison control system information reached only $1 \%$ of households. Outcome evaluation of the effectiveness of this program revealed no significant difference between the risk of poisoning between the intervention and control communities.

Paraffin poisoning is common in South African children so Krug et al implemented a program which included distribution of up to 20000 CRCs to households in one geographical district and compared the subsequent incidence of paraffin poisoning in this area to a control district that did not receive CRCs. ${ }^{15}$ Both the study and control communities received health education. Baseline data collected retrospectively showed a similar age distribution of children ingesting paraffin and a similar seasonal variation with more ingestions occurring in summer months. The intervention resulted in a remarkable $47 \%$ reduction in the incidence of paraffin poisonings in the study community compared with no change in the incidence in the control community. These results indicate that the CRCs were a successful initiative in the target community but that the ongoing health education given in both communities was not making an impact on incidence rates.

\section{Studies evaluating a community based intervention using an historical control design}

A program combining education and mass media initiatives to prevent poisoning in preschool children was implemented in one county in South Carolina, United States with the percentage decline in hospitalized children for accidental poisoning examined as the outcome measure. ${ }^{16}$ This program was implemented against a background national trend of falling rates of injury deaths. No data were collected relating to this nor was any attempt made to model secular changes or social level variables that may have confounded the study results. Historical data over three years for the one county showed between $23 \%-29 \%$ reduction each year in hospitalized poisonings for children aged $0-5$ years when compared with the baseline measure before the program. Few details of the intervention program are given in the paper and without comparative control data or an examination of national trends it is difficult to attribute the reduction in hospitalized accidental poisonings solely to the county initiated program.

The impact of a World Health Organization Safe Community model on the incidence of poisonings for children aged $0-15$ years was evaluated by Lindqvist et al. ${ }^{17}$ While the safe community of Motala, Sweden was assigned a control community for comparison of minor, moderate, and severe injuries of all types in children, only historical analysis from the safe community was presented for ingestion injuries. Results indicate a post-program reduction in ingestions for all children aged $0-15$ years and specifically for the 0-6 year and 7-12 year age groups. The incidence actually rose in the 13-15 year age group, however, the numbers are very small and subsequently the confidence limits reported are wide. They included, for each age group, the null value and indicated the program may not have had any effect. In their analysis of all injuries there was also a 
Table 1 Studies of community based programs to prevent poisoning in children aged 0-15 years

\begin{tabular}{|c|c|c|c|c|c|c|}
\hline Study & $\begin{array}{l}\text { Location/community/ } \\
\text { size/demographic }\end{array}$ & $\begin{array}{l}\text { Time frame for } \\
\text { intervention }\end{array}$ & Type of control & Type of intervention & $\begin{array}{l}\text { Outcomes measures/ } \\
\text { method }\end{array}$ & Results \\
\hline \multicolumn{7}{|c|}{ Studies designed with community controls } \\
\hline \multirow[t]{2}{*}{$\begin{array}{l}\text { Guyer et al, } \\
1989^{14}\end{array}$} & $\begin{array}{l}\text { Nine cities in } \\
\text { Massachussetts, USA. } \\
\text { Total population: } \\
139810\end{array}$ & $\begin{array}{l}\text { September } \\
\text { 1980-June } 1982\end{array}$ & $\begin{array}{l}\text { Five control } \\
\text { communities matched } \\
\text { initially from } 1970 \\
\text { census data on } \\
\text { demographics: total } \\
\text { population } 146866\end{array}$ & $\begin{array}{l}\text { Targeted education. } \\
\text { Mass media education }\end{array}$ & $\begin{array}{l}\text { Injuries in children } \\
\text { aged 0-5 years } \\
\text { requiring emergency } \\
\text { department or hospital } \\
\text { treatment or resulting in } \\
\text { death. } \\
\text { Injury cases recorded at } \\
23 \text { hospitals based on a } \\
\text { surveillance system } \\
1979-82\end{array}$ & $\begin{array}{l}\text { Crude incidence rates } \\
\text { (per } 10000 \text { per year) } \\
\text { for poisoning: } \\
\text { Intervention-before } \\
31.76 \text {, after } 36.14 \text {. } \\
\text { Control-before } \\
92.71 \text {, after } 92.71\end{array}$ \\
\hline & & & $\begin{array}{l}\text { NB: by 1980, control } \\
\text { communities did } \\
\text { actually differ } \\
\text { demographically with } \\
\text { higher proportions of } \\
\text { poorer and Hispanic } \\
\text { households. This led to } \\
\text { higher baseline injuries. } \\
\text { SES controlled for in } \\
\text { analysis }\end{array}$ & & & $\begin{array}{l}\text { SES adjusted odds } \\
\text { ratio for poisoning in } \\
\text { pre-intervention } \\
\text { period versus post } \\
\text { intervention for } \\
\text { intervention } \\
\text { community v control is } \\
0.95(95 \% \mathrm{Cl} 0.57 \text { to } \\
1.58 \text { ) }\end{array}$ \\
\hline $\begin{array}{l}\text { Krug et al, } \\
1994^{15}\end{array}$ & $\begin{array}{l}\text { Gelukspan district, } \\
\text { Western Transvaal, } \\
\text { Bophuthatswana, } \\
\text { South Africa. } \\
\text { Population } 94000 \\
\text { (1985), assumed } \\
\text { population growth of } \\
3 \% \text { annually }\end{array}$ & $\begin{array}{l}\text { Baseline data } \\
\text { collected } \\
\text { (retrospectively) } \\
\text { 1988-90 } \\
\text { Intervention Nov } \\
\text { 1991-Dec } 1992\end{array}$ & $\begin{array}{l}\text { Lehurutshe district } \\
\text { Population } 72000 \\
\text { assumed similar in } \\
\text { demographics. } \\
\text { Received health } \\
\text { education messages }\end{array}$ & $\begin{array}{l}\text { Targeted education. } \\
\text { Changes to } \\
\text { environment }\end{array}$ & $\begin{array}{l}\text { Hospital and clinical } \\
\text { records - child } \\
\text { poisoning due to } \\
\text { ingestion of paraffin }\end{array}$ & $\begin{array}{l}\text { Incidence of paraffin } \\
\text { ingestion declined by } \\
47 \% \text { in intervention } \\
\text { area, remained } \\
\text { constant in control } \\
\text { area }\end{array}$ \\
\hline \multicolumn{7}{|c|}{ Studies designed with the intervention community as an historical control } \\
\hline $\begin{array}{l}\text { Maisel et al, } \\
1967^{16}\end{array}$ & $\begin{array}{l}\text { Charleston County, } \\
\text { Southern Carolina, } \\
\text { USA }\end{array}$ & $1962-65$ & Historical control & $\begin{array}{l}\text { Targeted education. } \\
\text { Mass media education }\end{array}$ & $\begin{array}{l}\text { Children under the } \\
\text { age of } 5 \text { years } \\
\text { hospitalized for acute } \\
\text { accidental poisoning } \\
\text { National clearinghouse } \\
\text { for poison control centers }\end{array}$ & $\begin{array}{l}\text { 1960-61: } 90 \\
\text { (baseline) } \\
\text { 1962: 66, }-27 \% \text {, } \\
\text { 1963: 69, }-23 \% \text {, } \\
\text { 1964: 64, }-29 \%\end{array}$ \\
\hline $\begin{array}{l}\text { Lindqvist et al, } \\
2002^{17}\end{array}$ & $\begin{array}{l}\text { Motala, Ostergotland, } \\
\text { Sweden }\end{array}$ & $\begin{array}{l}\text { Program started in } \\
1985 . \\
\text { Pre-data collected } \\
\text { 1983-84. Post-data } \\
\text { collected } 1989\end{array}$ & $\begin{array}{l}\text { Historical control } \\
\text { results only reported } \\
\text { for ingestions }\end{array}$ & $\begin{array}{l}\text { Targeted education. } \\
\text { Mass media education. } \\
\text { Changes to } \\
\text { environment. } \\
\text { Behavioural strategies. } \\
\text { WHO safe community } \\
\text { approach }\end{array}$ & $\begin{array}{l}\text { Ingestion injuries in } \\
\text { children aged 0-15 } \\
\text { years treated at health } \\
\text { care units and local } \\
\text { hospital. Comparing } \\
\text { pre-intervention } \\
\text { (1984-14) and post } \\
\text { (1989) data. } \\
\text { Odds ratios giving } \\
\text { changes in injury rates } \\
\text { after } v \text { before intervention }\end{array}$ & $\begin{array}{l}\text { Aged 0-6 years: OR, } \\
0.59 \text { (95\% Cl } 0.29 \text { to } \\
1.19 \text { ) } \\
7-12 \text { years: OR, } 0.16 \\
\text { (95\% Cl } 0.02 \text { to } 1.32 \text { ) } \\
13-15 \text { years: OR, } \\
1.65 \text { (95\% Cl } 0.28 \text { to } \\
9.91) \\
0-15 \text { years OR } 0.60 \\
(95 \% \mathrm{Cl} 0.33-1.10) \\
n\end{array}$ \\
\hline
\end{tabular}

post-program reduction found in the control community, which the authors state was subject to a national injury prevention program at the time of their study. It is not possible to determine if the historical reduction shown in ingestions within the Motala community was due to the poisoning prevention program or the national injury prevention program in place.

\section{DISCUSSION}

This paper reports a systematic review of the scientific literature relating to high quality evidence of the effectiveness of community based interventions to reduce poisoning mortality and morbidity in children $0-15$ years of age. Only four relevant papers were identified, ${ }^{14-17}$ and only two of these used a trial design with a contemporary community control. ${ }^{14}{ }^{15}$ Only one study provided convincing evidence of an effective community program for reducing poisoning in children. $^{15}$

The evidence presented in this review supports the conclusion that CRCs (as a countermeasure in its own right) are effective in reducing poisoning in young children and that community based interventions are an effective way of implementing this countermeasure. The finding that CRCs are effective in a community intervention study in Africa some 20 years after CRCs were widely introduced into high income economies raises two issues: the transferability of injury prevention interventions across cultural and political boundaries, and the perceived importance for replicating evaluations of apparently successful interventions when used in different sociocultural settings. It would appear that this study was in part conducted to test the hypothesis (and convince local authorities) that an apparently effective intervention in one country could be applied successfully to another. The findings of this study would also suggest that targeted strategies dealing with only one substance may be more effective than a general poisons prevention approach. $^{15}$

\section{IMPLICATIONS FOR PREVENTION}

Evidence in this review suggests that community based education campaigns alone lead to no measurable reduction of poisoning in children. ${ }^{14}{ }^{15}$ This review raises two important 


\section{Key points}

- Community based models for injury prevention have become an accepted part of the overall injury control strategy.

- There is a paucity of research studies in the literature from which evidence regarding the effectiveness of community based childhood poisoning prevention programs can be obtained.

- A systematic review of the literature found only four studies of community based poisoning prevention programs that included an evaluative component of poisoning rates and only two studies that used a trial design with a contemporary control.

- High quality evaluations of community based poisoning prevention programs are required to determine if these programs achieve population level improvements in injury outcomes.

issues. The first relates to the need for high quality community based intervention programs to implement what research has shown to be efficacious countermeasures in research settings. The second relates to the need to demonstrate through high quality evaluations, these programs are able to achieve population level improvements in injury outcomes. In the area of childhood poisoning prevention further work is clearly needed to advance both these issues.

\section{ACKNOWLEDGEMENTS}

The research reported in this publication is a project of Injury Prevention and Control (Australia) Ltd (www.ipca.com.au), supported by a grant from the National Health and Medical Research Council.

\section{Authors' affiliations}

J Nixon, Department of Paediatrics and Child Health, School of Medicine, University of Queensland, Brisbane, Australia
A Spinks, C Turner, R McClure, Injury Research Unit, School of Population Health, Mayne Medical School, University of Queensland, Brisbane, Australia

\section{REFERENCES}

1 Sleet DA, Schieber RA, Gilchrist J. Health promotion policy and politics: lessons from childhood injury prevention. Health Promotion Practice 2003:4:103-8.

2 Rivara FP. Traumatic deaths of children in the United States: currently available prevention strategies. Pediatrics 1985;75:456-62.

3 Dowsell T, Towner EML, Simpson G, et al. Preventing childhood unintentional injuries - what works? A literature review. Inj Prev 1996;2:140-9.

4 Chien C, Marriott JL, Ashby K, et al. Unintentional ingestion of over the counter medications in children less than 5 years old. J Paediatr Child Health 2003;39:264-9.

5 Ozanne-Smith J, Day L, Parsons B, et al. Childhood poisoning: access and prevention. J Paediatr Child Health 2001;37:262-5.

6 Hoy JL, Day LM, Tibballs J, et al. Unintentional poisoning hospitalisations among young children in Victoria. Inj Prev 1999;5:31-5.

7 Reith DM, Pitt WR, Hockey R. Childhood poisoning in Queensland: an analysis of presentation and admission rates. J Paediatr Child Health $2001 ; 37: 446-50$

8 Yates KM. Accidental poisoning in New Zealand. Emerg Med 2003; 15:244-9.

9 Sibert JR, Routledge PA. Accidental poisoning in children: can we admit fewer children with safery? Arch Dis Child 1991;66:263-6.

10 Moller J. Community-based interventions: an emerging dimension of injury control models. Health Promotion Journal of Australia 1991;1(2):51-5.

11 Wiseman HM, Guest K, Murray VSG, et al. Accidental poisoning in childhood: a multicentre survey 2 . The role of packaging in accidents involving medications. Human Toxicology 1987;6:303-14.

12 Gielen AC, McDonald EM, Wilson MEH, et al. Effects of improved access to safety counseling, products, and home visits on parents' safety practices. Arch Pediatr Adolesc Med 2002;156:33-40.

13 Zaza S, Wright-De Aguero LK, et al. Data collection instrument and procedure for systematic reviews in the Guide to Community Preventive Services. Am J Prev Med 2000;18:44-74.

14 Guyer G, Gallagher SS, Chang BH, et al. Prevention of childhood injuries: evaluation of the Statewide Childhood Injury Prevention Program (SCIPP). Am J Public Health 1989;79:1521-7.

15 Krug A, Ellis JB, Hay IT, et al. The impact of child-resistant containers on the incidence of paraffin (kerosene) ingestion in children. $S$ Afr Med J 1994;84:730-4.

16 Maisel G, Langdoc BA, Jenkins $M Q$, et al. Analysis of two surveys evaluating a project to reduce accidental poisoning among children. Public Health Rep 1967;82:555-60.

17 Lindqvist K, Timpka T, Schelp L, et al. Evaluation of a child safety program based on the WHO Safe Community model. Inj Prev 2002:8:23-6.

18 Kemp A, Gibbs N, Vafidis G, et al. Safe Child Penarth: experience with a Safe Community strategy for preventing injuries to children. Inj Prev 1998;4:63-8.

19 Lacourtre P, Minisci M, Gouveia WA, et al. Evaluation of a community-based poison education program. Clin Toxicol 1978;13:623-9.

20 Nicholson AJ, Duff S, Mullan C, et al. The use of local accident and emergency injury surveillance to monitor the impact of a lay safety community programme. Ir Med J 2002;95:143-5. 